\title{
Decision Making And Systems Thinking: Educational Issues
}

\author{
M. Kudret Yurtseven, Izmir University, Turkey \\ Walter W. Buchanan, Texas A\&M University, College Station, USA
}

\begin{abstract}
Decision making in most universities is taught within the conventional OR/MS (Operations Research/Management Science) paradigm. This paradigm is known to be "hard" since it is consisted of mathematical tools, and normally suitable for solving structured problems. In complex situations the conventional OR/MS paradigm proves to be inadequate; decisions must be based on systems thinking which provides the decision maker(s) the opportunity to address the problematic situation in its full system context. The aim here is to develop a framework and a new course to teach "decision making through systems thinking" to industrial engineering students. The new course is to be taken after the existing course which covers the traditional OR/MS paradigm. It is believed that such an "extended" framework will help students to improve their skills in handling complex decision situations.
\end{abstract}

Keywords: Decision Making; Systems Thinking; Industrial Engineering Education; OR/MS Paradigm; Problem Structuring Methods

\section{INTRODUCTION}

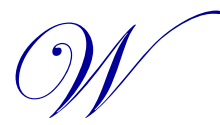

hen decision making is taught within the framework of classical management scienceloperations research (MS/OR) paradigm, which sometimes is referred as hard operations research, the emphasis is usually put on the mathematical tools and techniques. In cases where the problematic situation can be clearly described, there are various tools available for decision making; such as mathematical programming, game theory, simulation models, Markov chain models, decision tress, etc. However, in other cases, such as in decision situations faced by top managers, there may be too much ambiguity about the objective and decision options. Sometimes the information and knowledge available to make an effective decision may be uncertain, incomplete, or even distorted. Under such conditions the problematic situation must be described in its full system context. As early as 2005 Jamali warned that the existing decision-making processes are no longer adequate, and urged educational institutions to teach newly developing decision-making paradigms (Jamali, 2005). In complex situations there are actors with differing goals, preferences, and perceptions. The organizational structure, culture, and personal inclinations of managers influence the decision making process. The difficulties involved become more pronounced when there are rapid changes in the internal and external dynamics of the organization - particularly in external dynamics. Organizations can survive and grow only if they can adapt themselves to this fast change. The change forces adaptation, and adaptation is required in many dimensions including the existing decision making processes. According to Hummelbrunner and Williams (2011), there are three main principles in managing complexity: decentralization, collaborative and adaptive management. GorzenMitka, et. al. (2014) defend a similar position, arguing that strategic decision-making in complex environments requires meta-cognitive skills and a tool-bag for innovative and adaptable decision models beyond linear thinking.

Complexity has always been one of the central concepts in systems movement. Gorze-Mitka, et.al. (2014) traces the roots of "modern complexity" to the birth of General Systems Theory which was pioneered by Ludwig von Bertalanffy. The complexity issue was also addressed in Weiner's work on cybernetics and in the work of other important names in systems movement, such as Churchman, Ackoff, Beer, Weinberg, Forrester, and Gigch (Skyttner, 2001 and 2006) . Snyder (2013) points out that researchers at the Santa Fe Institute attempted to unify some of the core system concepts into a model known as complex adaptive systems which still is an evolving construct. It is argued that emergent properties of complex systems can be modeled and operated relatively more effectively as complex adaptive systems. (Aelker, et. al. 2013) and (Satkamaya, et, al, 2014) discuss the approach 
and its applications in some depth.

There are various studies that specifically address complexity decision making via holistic or systems approach. For instance, Sondoss et.al. (2015) handle the complexity in a viticulture irrigation management System in South Australia. They present a step-wise methodology that integrates qualitative information into formal simulation models, involving cognitive mapping and agent based modelling approaches. The resulting structure seems to be capturing the richness of decision making and mental models. Pagani and Otto (2013) adopts qualitative mapping theory building and quantitative group model building approaches in a computer-based system modeling environment for market startegy development. They claim that this holistic apparoach enhances the quality of the decision processes. Carlman, et.al. (2014) relate the complexity issue to sustainability in decision making processes, particularly in ecological systems. The decision structure developed provides communication and collaboration between a technical-scientific group and social scientists via a holistic outlook. Swami's work (2013), on the other hand, views decision making under the broad topic of executive functions or cognitive processes that regulate, control, and manage other cognitive processes. This holistic approach includes theories and concepts from psychology, behavioural economics, operations research, and managerial practice. Schiuma, et.al. (2012) report a systems thinking-based framework where knowledge assets are translated into organizational value for making good decisions. Similarly, Wiek, et.al.'s study (2009) presents a framework called The Transdisciplinary Integrated Planning and Synthesis (TIPS), which is mainly based on soft OR methods. This particular framework makes use of a multi-methodological approach involving cognitive skills and habits of the stakeholders, and experts and their mutual and joint transdisciplinary learning processes. This framework was applied in a large-scale regional planning process in Switzerland. The interested reader can find a number of models/methods/systems that have been developed to underpin sustainable decision-making in environmental impact assessment, life cycle assessment, ecological footprints, cost benefit analysis, etc. (Sondoss, et. al., 2015), (Carlman, et. al., 2014), (Schiuma, et. al., 2012), (Petkov, et. al., 2009) and (Taylor, et. al., 2011).

The material in the paper will be presented in the following order: the fundamental role of system thinking in decision making is assessed in the next section; this will be followed by sections on potential contributions of systems thinking in decision making, and the description of the framework and the new course developed.

\section{Systems Thinking and Decision Making}

Systems thinking developed over the last decades to overcome the inadequacies of classical science and to search for solutions to complex problematic situations in a holistic manner. Although quite impressive developments occurred in the last decades, there is still plenty of work to do in systems thinking area. Back in 1993, Hitchins (1993) suggested that "the present approach is short-lived, rigid, and expensive" - meaning systems thinking. He proposed that we should learn from nature, and conceive higher order adaptive systems using genetic methods. According to him, adopting an accelerated evolutionary approach by building complex adaptive socio-technical systems, without fully understanding the incomprehensible complex human-system interaction is needed (Hitchins, 2003). The 2020 vision of Systems Engineering (SE) published by INCOSE (International Council on Systems Engineering) also suggests that developments in genetics and technology will make significant contributions to SE (INCOSE, 2005). Similar views were expressed by other researchers in the past, including Skyttner (2001 and 2006). According to him, the old worldview has not been kept up to date to take account of contemporary change and the world society and its institutions are not functioning effectively. He suggests a transformation from the reactive view into a predictive and anticipatory mode. Despite some shortcomings, a variety of significant soft systems methodologies have been developed since the 1980s that overcame some of the limitations of the hard school (Jackson, 2000 and 2003), (Maani, et.al. 2007), (Mingers, et.al. 2010), (Mingers, 2010 and 2011), and (Yurtseven and Buchanan, 2012).

Probably the most important "break away" from the hard school is related to the concept of objectivity. The claim of "objectivity" of classical science is found to be problematic in a soft systems school; it is seen as nothing but an illusion. It is argued that it is meaningless to formulate objective aims and objective means in complex situations. The actors involved in the process are bound to have different perspectives of the problematic situation or the reality, and they will highly likely suggest different solutions. For instance, Soft Systems Methodology (SSM), one of the well known methodologies, developed by Checkland, embraces a paradigm of learning rather than viewing the world as systems whose performance can be optimized by following systematic procedures (Checkland and Scholes, 1990) and (Checkland, 1993). The conventional system methodologies such as System Analysis, Systems 
Engineering, Hard Operations Research, System Dynamics, (Hard) Cybernetics are based on systematic procedures. The tendency seen in SSM can also be found in other soft methodologies, such as Warfield's Interactive Management, Churchman's Social Systems Design, Mason and Mitroff's Strategic Assumption Surfacing and Testing, Ackoff's Social Systems Sciences, Senge's Systems Thinking, Soft OR, Soft System Dynamics, and Soft Cybernetics.

\section{Methodology Selection}

One of the most difficult tasks in a decision-making process is to choose the "best" methodology available, like in all complex system studies. According to Jackson (2003), selection of the appropriate methodology for any type of systems study is related the context of the problem - this is obviously true also for decision making. Jackson's view is illustrated in Table 1. Here, six ideal-type forms of problem context are given by combining the 'systems' and 'participants' dimensions. They are simple-unitary, simple-pluralist, simple-coercive, complex-unitary, complexpluralist and complex-coercive. Jackson (2003) then relates the problem context to different classes of systems methodologies as shown in Table 2. Here, the corresponding methodologies are classified as (1) Functionalist Systems Approach, (2) Interpretive Systems Approach, (3) Emancipatory Systems Approach, (4) Postmodern Systems Approach, and (5) Critical Systems Thinking.

Table 1. Jackson's extended version of Jackson and Keys' 'ideal' grid of problem contexts (Jackson, 2003).

\begin{tabular}{c|c|c|c}
\hline SYSTEMS & Unitary Participant & Pluralist Participation & Coersive Participation \\
\hline Simple & Simple-Unitary & Simple-Pluralist & Simple- Coersive \\
\hline Complex & Complex-Unitary & Complex-Pluralist & Complex- Coersive \\
\hline
\end{tabular}

Table 2. Systems approaches related to problem contexts in the System of Systems Methodologies (SOSM) (Jackson, 2003).

\begin{tabular}{c|c|c|c}
\hline SYSTEMS & Unitary Participant & Pluralist Participation & Coersive Participation \\
\hline Simple & Hard Systems Thinking & Soft Systems Approaches & $\begin{array}{c}\text { Emancipatory Systems } \\
\text { Thinking }\end{array}$ \\
\hline Complex & $\begin{array}{c}\text { System Dynamics } \\
\text { Organizational Cybernetics } \\
\text { Complexity Theory }\end{array}$ & Soft Systems Approaches & $\begin{array}{c}\text { Post Modern Systems } \\
\text { Thinking }\end{array}$ \\
\hline
\end{tabular}

The reader should note that hard systems thinkers work in that grid of problem contexts where it is assumed that people share values and beliefs, and that systems are simple enough to be mathematically modeled. The simpleunitary approach is known to be successful in tackling a whole variety of operational issues (such as, inventory, queuing, scheduling, and routing problems), but it fails in complex situations. In complex-unitary situations, System Dynamics, Organizational Cybernetics and Complexity Theory can be useful while complex-pluralistic situations can be resolved via soft system approaches. Needless to say, it is not possible to draw clear lines between different systems and different problem categories as shown in the above tables, but they provide vital clues to decision makers. The reader is reminded that Critical Systems Thinking is recommended when a variety of methodologies, methods and models need to be employed simultaneously in complexity (Jackson 2000 and 2003) and (Flood et. al., 1998).

The methodology-problem context issue is also addressed by (Kurtz, et.al., 2003). Their framework is is shown in Table 3 and known as the "Cynefin sense-making framework" (Maani, et.al.,2007). Systems are classified as Known, Knowable, Complex and Chaos. The Known systems are systems that have perceivable and predictable cause-and-effect relationships and can be handled via Sense-Categorize-Respond type methodologies (e.g. process re-engineering). In the Knowable category, cause and effect are separated over time and space, and Sense-AnalyzeRespond type methodologies are suitable - e.g. System Dynamics (Maani,et.al., 2007). Complex systems, on the other hand, are viewed as systems with cause-and-effect relationships that are coherent in retrospect and do not repeat; the appropriate methodologies for this category are the Probe-Sense-Respond type (e.g. pattern management). Cause-and-effect relationships are not perceivable in chaotic systems and can be handled only by the Act-Sense-Respond approach (e.g. crisis management). As mentioned before, drawing clear boundaries between different classes is not possible. The reader should note that the types of decision problems considerd in this study fall into the Known and Knowable regions. 
Table 3. The Cynefin sense-making framework

COMPLEX

\section{KNOWABLE}

- Cause and effect are only coherent in retrospect and do not repeat

- PatternManagement

- Perspective filters

- Complex adaptive systems

- Probe-Sense-Respond

- No cause and effect relationship perceivable

- Stability-focused intervention

- Enactment tools

- Crisis Management

- Act-Sense-Respond
- Cause and effcet separated over time and space

- Analytical/Reductionist

- Scenario Planning

- Systems thinking

- Sense-Analyze-Respond

- Cause and effect relations repetable, perceivable and predictable

- Legitimae best practice

- Standard operating procedures

- Process re-engineering

- Sense-Categorize-Respond

When it comes to the classification of decision making methods, Pownall (2012) gives us a useful picture. The four categories are:

(a) A qualitative perspective which is an integrative approach (or rational normative).

(b) A perspective achieved by combining quantitative and behavioral disciplines in an interdisciplinary manner.

(c) An interlocking perspective where the engagement of one perspective limits the use of other perspectives.

(d) A cause-effect view where decisions taken are interrelated across organizational events.

Systems thinking-based decision making does not exclude perspectives (a), (b) and (d). Furthermore, it removes the limitations implied by (c). Figure 1 shows the relative positions of different approaches as a function of changing complexity. While sequential decision making (problems are formulated as a sequence of "independent" decisions) is very algorithmic, appearing at the left of the scale, anarchical decision making is far on the right. The RAT (rational- normative model of decision making) and three-phased (problem identification, solution development, and solution selection) models are closer to sequential decision making, respectively, and heuristic models are closer to the other edge.

Figure 1. Moving beyond RAT (rational model of decision making) (Pownall, 2012).

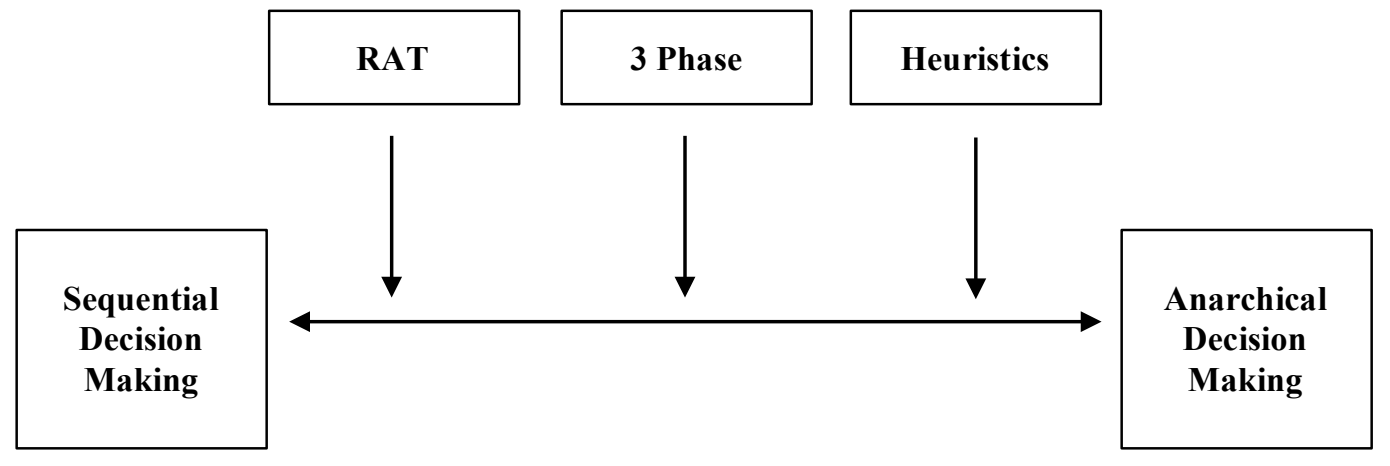

The normative or rational models are based on the assumption that all relevant and pertinent information is available for optimal decision making-such as in cost-benefit analysis. The three-phased model, on the other hand, recognizes that the solution development and solution selection are not separate cognitive processes as they are in the RAT model; these processes overlap and can occur simultaneously. Moving to the right in the figure makes decision processes more complicated since cohesive groups emerge in highly pressurized and often political context. As one goes towards "Anarchical Decision Making" region, the need to make use of heuristic approaches becomes inevitable. The models here tend to become more "irrational" where human decision values are incorporated into the 
process. The decision maker may incorporate any of these models in systems thinking-based approach.

Monte Carlo Modeling can also be a useful tool in complex decisions making situations (Pownall 2012, Parnell, et.al. 2011, Taylor III, 2013). The decision maker does not need to rely upon measurable input data or subjective estimates of likelihoods of given events occurring, and does not need to know the assumptions behind the patterns for success or failures in the environment. Instead, potential outcomes of a decision problem are assigned weights via the use of pseudo random numbers, allowing the decision maker to produce decisions without referring to the decision context. In this way, the difficulty involved in the explicit treatment of uncertainty is avoided, thanks to the extensive use of computers. Due to its versatility, Monte Carlo modeling is covered in many textbooks today (Hazelrigg, 1996), (Daellanbach, 2005), (Parnell, et. al. 2011), (Krajewski, et. al., 2013) and (Taylor III, 2013).

\section{The Framework and New Course Proposed}

The following framework is designed to guide instructors in teaching "Decision Making" to undergraduate students who are expected to face various different situations in industry, whether simple or complex. It is made up of five parts: Fundamentals; Rational Models with Quantitative Methods; Rational Models with Qualitative Methods; Holistic Decision Models; Optional Material. The instructor may design a suitable course or a set of courses to satisfy the needs of her/his students.

\section{Part I: The Fundamentals: Introduction to Effective Decision Making}

The objective here is to explore the duality of the decision-making process, which is partly science and partly art. Different concepts of rationality and the resulting approaches are discussed in general terms, ranging from normative rational view to anarchistic and heuristic views.

Part II: Rational Models with Qualitative Methods and Analysis

The main theme here is to cover the development of rational models based on forecasting and regression techniques.

Part III: Rational Models with Quantitative Methods and Analysis

This section covers methods based on probability theory, such as decision trees and related decision analysis and queuing theory.

\section{Part IV: Holistic Decision Models}

This part starts with the Fundamentals of Systems Thinking and provides an introduction to soft system methodologies. Some case studies will be discussed to demonstrate the strengths of system thinking-based decision making. Selection of case studies and the methodology or methodologies will depend on the instructor's choice.

\section{Part V: Optional Material}

Heuristic Decision Making and Group Decision Making: This section includes the fundamentals of decision making approaches that emphasize cognitive, heuristic, and group behavior aspects (Pownall, 2012).

Knowledge Management and Decision Enhancing Decision Making (Optional): The objective in this section is to teach the fundamentals of knowledge management concepts, and (intelligent) decision support systems, together with the relevant IT. The technological aspects of this topic may be found at (Muller, et. al., 2014), (Khan, et. .al. 2014), (Laudon, et.al, 2013) and (Kendall, et. al. 2011).

The syllabus of the new course designed in this study is as follows:

Course Code and Title: IEN 4XX Decision Making Through Systems Thinking 
Course Objectives: The aim in this course is to teach systems thinking-based decision making techniques in complex situations. First, major systems concepts are covered, followed by a discussion of the basics of systems thinking. Next, a comparative view of hard and soft systems thinking, issues in methodology selection and an overview of Critical Systems Thinking are presented. The rest of the course is dedicated to discussion of case studies where decision making takes place in complex environments. Most of the case studies presented make use of System Dynamics approach where hard and soft modeling approaches are combined

Learning Objectives: (1) To develop a satisfactory background in systems thinking and soft systems thinking; (2) to learn major system concepts; (3) To learn how to develop the description of a complex decision making situation in a system context; (3) How to develop a model of a complex situation via hard and soft modeling approaches;(4) How to produce a decision via an appropriate system methodology or methodologies.

Prerequisite: Background on OR/MS Paradigm and Rational Decision Making

\section{Course Outline}

1. Introduction: Complexity and Decision Making

2. Historical Development of Systems Thinking and Major System Concepts

3. Comparison of Hard and Soft System Thinking Paradigms

4. Problem Context and Methodology Selection

5. Multi-Methodological Approach and Critical Systems Thinking

6. Models in Decision Making and Decision Making in Complexity; Case Studies

7. System Dynamics Methodology (Problem Structuring via Hard and Soft Modeling, Computer Simulation, Policy Analysis and Decision Making); Case studies

In any methodology, problem structuring or description of the problematic situation is a very important step. The decision maker needs to know the major system concepts to develop a satisfactory description of the problematic situation. The important system concepts such as system boundary, types of systems and models (discrete /continouos systems, deterministic/stochastic systems, linear/non-linear systems, closed/open systems), feedforward/feedback loops, open-loop/closed-loop control mechanisms, transient/steady-state behavior, emergent behavior, system hierarchies and system response lags are covered early in the course. Students need to understand the diagrams shown in Figure 2.a and 2.b; they provide a comparison of problem structuring by the hard OR methodology and Systems Thinking (Daellanbach, 2005). While System S (the narrow system of interest) and System M (the modeling system) are separate in the hard OR methodology, System S is defined within System M in the soft approaches. This makes a significant difference in problem structuring or problem formulation, suggesting that soft systems approaches have a better chance of being successful. The reader should also note the inputs used in the definition of System S. In addition to boundary judgments, controllable and uncontrollable inputs, similar to case in the hard OR methodology, there is a richer group of inputs in the soft systems approach. Inputs such as technology, facilitation, problem structuring, reflective thinking and commitment for action allow the decision maker to capture the problematic situation in its full system context.

Several tools such as mind maps, rich picture diagrams, and cognitive maps will also be taught in the course are available for structuring a problematic situation. Good problem structuring requires good system boundary selection, which fixes the scope, providing direction and focus for all subsequent analysis. Poor boundary selection may have serious consequences, particularly as far as people affected by the decision and the resources involved. Furthermore, a holistic perspective given in Figure 2.b allows the decision makers to see unplanned and counterintuitive outcomes with relative ease and help to evaluate the consequences.

In the modeling section, students will learn how to include soft indicators together with hard indicators (key performance indicators or critical success factors). The soft indicators include such things as morale, commitment, burnout, care for customers and capacity for learning. Last but not the least, system simulation is certainly one of the powerful tools for conducting what-if analysis to make a good decision. Simulation models based on System Dynamics methodology are very popular in policy analysis, and in scenario and strategy development. There are quite a number of successful applications of the System Dynamics methodolgy in complex ecological systems, 
supply chains and large-scale healthcare systems (Maani, et.al., 2007, Aelker, et.al, 2013, Mingers, et.al. 2010, Yurtseven, et.al, 2012).

In short, the hard OR/MS paradigm needs to be complemented by soft system approaches in university education. This will broaden the vision of students and help them handle complex decision problems with confidence. Soft methodologies cover a wide range of approaches that hard methodologies cannot capture. This new course has not been taught in the form as described here yet. It will be offered in the coming academic year. However, a positive response was received from the fourth year industrial engineering students when some material on system life cycle models in the Fundamentals of Systems Engineering course was replaced by the introductory material of this proposed course (items \#1 to 5 in the new syllabus). The objective of Fundamentals of Systems Engineering is to teach the analysis and design of industrial and socio-economic systems. It is compulsory and the remaining part of the course is based on the applications of system dynamics methodology. It is believed that students' positive response to the change was primarily related to its relevance. They were able to integrate this material into industrial engineering profession as opposed to the fairly abstract material on system life-cycle methodology. Surely this initial information is not sufficient to judge whether the new approach is more or less successful. Like any other new course, particularly if it is not a conventional one, it has to be taught at least three times to measure its educational effectiveness. The results from the second offer of the course may not also be fully reliable since there tends to be some minor changes after the first offer. The next phase in this research work is to redesign the Socio-Technical System Design course accordingly. This is an elective course. Highly likely this course will be primarily based on Soft Systems Methodology.

Figure 2a. Structure diagram for hard OR methodology (Daellanbach, 2005)

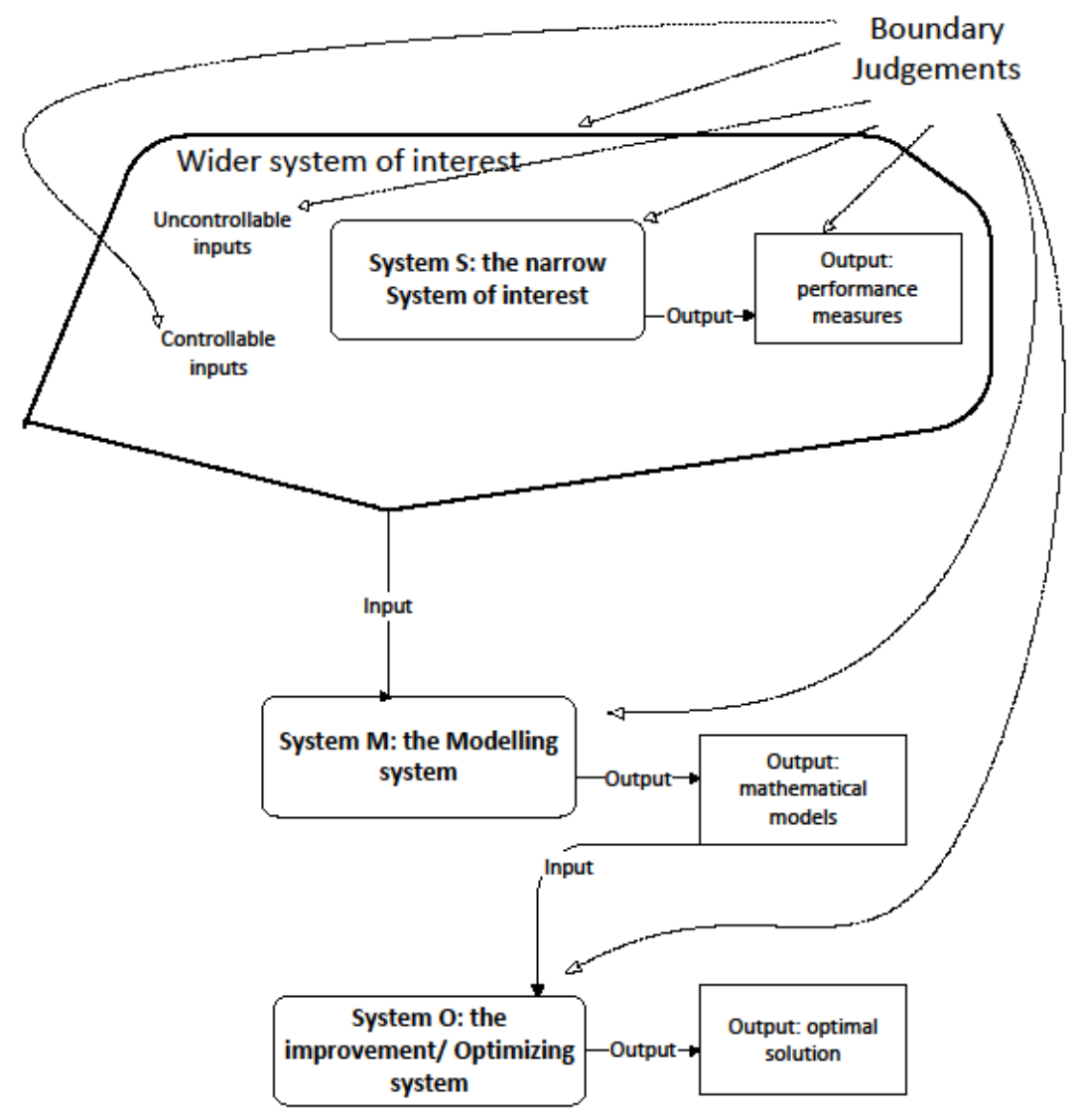


Figure 2b. Structure diagram for PSM (problem structuring method via systems thinking) (Daellanbach, 2005).

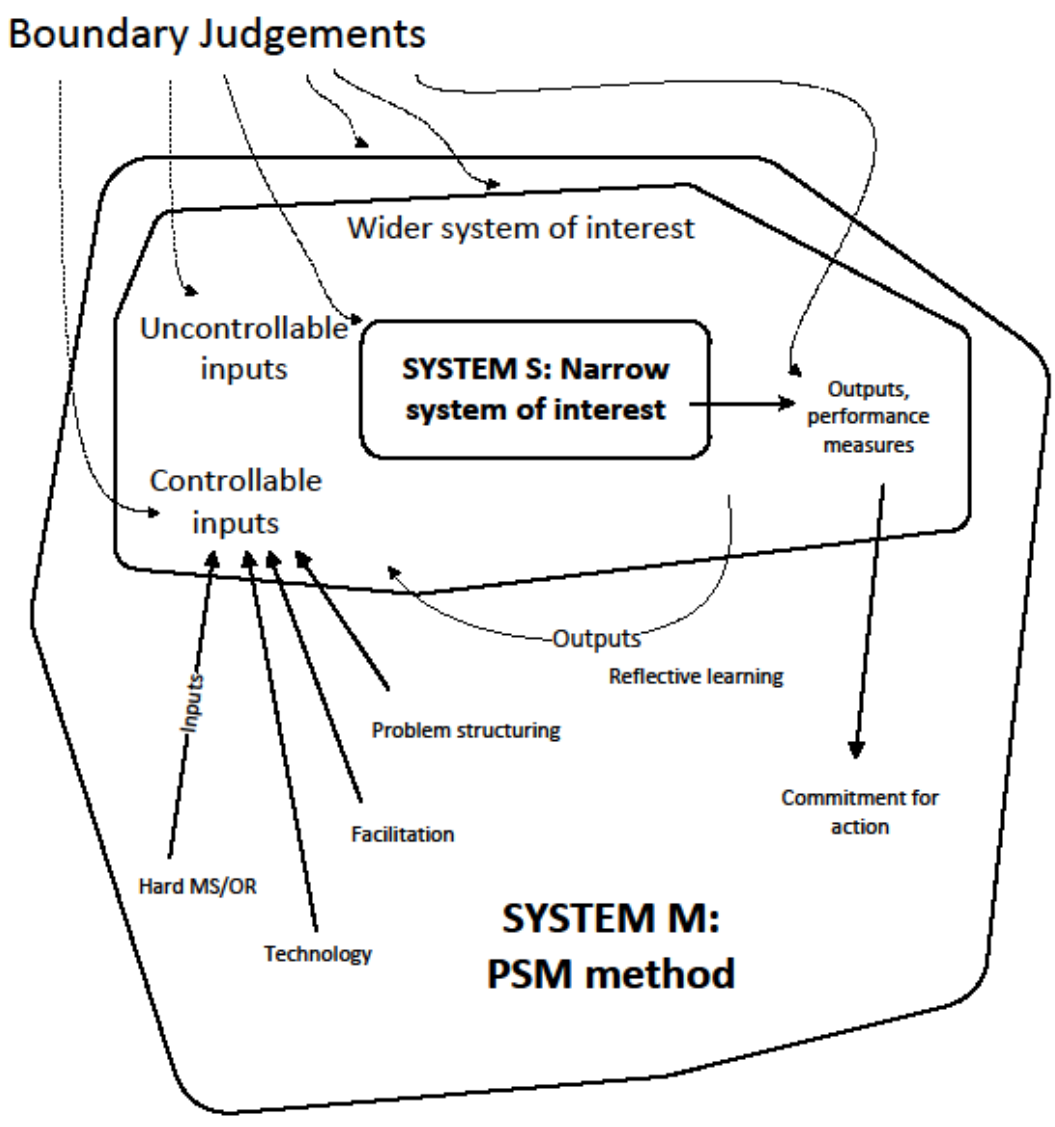

\section{CONCLUSIONS}

A new framework was developed and a new course was designed for teaching decision making to undergraduate students in this study. It was argued that the traditional or hard OR/MS paradigm is adequate for handling simple and structured decision making problems, but insufficient in complex situations. This weakness was overcome by expanding the traditional framework to include systems thinking-based methodologies. It was further argued that, through Systems Thinking, and through some soft methodologies, it is possible to develop a rich and a structured description of a messy problematic situation. This approach will help students in describing a complex problematic situation in a system context, and developing a satisficing decision through consensus within a pluralist environment - they will not be searching for an optimal solution for a simplified version of the complex reality. Future research will be directed towards measuring the degree of success of the new course in industrial engineering education via the learning objectives stated.

\section{AUTHOR BIOGRAPHIES}

M. Kudret Yurtseven, Ph.D., is an associate professor of Industrial and Systems Engineering. He taught and conducted research in several universities, including Purdue University at Indianapolis and Penn State Harrisburg. His areas of interest are Systems Engineering, Systems Modeling and Simulation and Complexity Management.

Walter W. Buchanan, Ph.D., is a Professor at Texas A\&M University. He is a Fellow and served on the Board of Directors of both ASEE and NSPE, is a past president of ASEE and the Massachusetts Society of Professional 
Engineers, and is a registered P.E. in six states. He is a past member of the Executive Committee of ETAC of ABET and is on the editorial board of the Journal of Engineering Technology.

\section{REFERENCES}

Aelker, Judith, Bauernhans, T., and Ehm, H. (2013) Managing complexity in supply chains: A discussion of current approaches on the example of the semiconductor industry, Procedia CIRP 7 ( 2013 ) $79-84$.

Carlman, I., Grönlund, E. and Longueville, A. (2015) "Models and methods as support for sustainable decision- making with focus on legal operationalization", Ecological Modelling,306 (2015) 95-100.

Checkland, P., (1993), Systems Thinking, Systems Practice, Wiley.

Checkland P. and Scholes J. (1990), Soft Systems Methodology in Action, Wiley.

Daellanbch, H.G., D.C. McNickle and S. Dye [2005] Management Science: Decision-Making Through Systems Thinking, Pelgrave Macmillan.

Flood, R.L., and E.R. Carson, (1998), Dealing with Complexity: An Introduction to the Theory and Application of Systems Science, Plenum Press.

Gorze-Mitka, I. and Okreglicka, M. (2014) "Improving Decision Making in Complexity Environment", Procedia Economics and Finance, 16, $402-409$.

Hazelrigg, G.A. (1996) Systems Engineering: An Approach to Information-Based Design, Prentice hall.

Hitchins, D.K., (2003), Advanced Systems Thinking, Engineering, and Management, Artech House.

Hitchins, D.K., (1993), Putting Systems to Work, dl.acm.org.

Hummelbrunner, R. and B. Williams B. (2011) Systems Concepts in Action : A Practitioner's Toolkit Stanford, Calif : Stanford Business Books.

INCOSE, Systems Engineering Vision 2020, Version 1.5, November 26, 2005.

Jackson, M. C., (2000), Systems Approaches to Management, Kluwer.

Jackson, M.C., (2003), Systems Thinking: Creative Holism for Managers, Wiley.

Jamali D. (2005), Changing management paradigms: implication for educational institutions, Journal of Management Development, vol.24, 2005,pp. 104-105.

Khan, R.A. (2014) Business Intelligence: An Integrated Approach, International Journal of Management and Innovation Volume 6 Issue 2 (2014) 21.

Krajeski, L.J., L.P. Ritzman and M.K. Malhorta (2013) Operations Management: Processes and Supply Chains, Pearson.

Kutz, C. and Snowden, D.J., (2003), The New Dynamics of Strategy: sense-making in a complex- complicated world. IBM Systems Journal 42(3): 462-483.

Maani, Kambiz E., and R.Y. Cavana, (2007), Systems Thinking and System Dynamics: Managing Change and Complexity, Pearson - New Zealand, 2007.

Mingers, J. and L. White (2010) A review of the recent contribution of systems thinking to operational research and management science, European Journal of Operational Research 207 (2010) 1147-1161.

Mingers, J. (2011) Soft OR comes of age-but not everywhere! , Omega 39 (2011) 729-741.

Müller, R.M., S. Linders, and L. Ferreira (2010) Business Intelligence and Service-oriented Architecture: A Delphi Study, Information Systems Management, 27:168-187, 2010

Ngai, E.W.T.,Peng, S.,Alexander, P. And Moon, K.K. L. (2014) "Decision support and intelligent systems in the textile and apparel supply chain: An academic review of research articles", Expert Systems with Applications, 41, 81-91.

Pagani, M. and Otto, P. (2013), "Integrating strategic thinking and simulation in marketing strategy: Seeing the whole System", Journal of Business Research, 66, 1568-1575.

Parnell, G.S.(Ed.), Driscoll, P.J.(Ed.), Henderson, D.L. (Ed.) (2011) Decision Making in Systems Engineering and Management, Wiley.

Petkov, D., Petkova, O. Andrew, T. and Nepal, T. "Mixing Multiple Criteria Decision Making with soft systems thinking techniques for decision support in complex situations", Decision Support Systems, 43, 1615-1629. 2009.

Pownall, I (2012) Effective Decision Making: An Introduction, Ventus ApS.

Schiuma, G., Carlucci, D. and Sole F. (2012) “Applying a systems thinking framework to assess knowledge assets Dynamics for business performance improvement”, Expert Systems with Applications, 39, 8044-8050.

Skyttner, L., (2001), General Systems Theory: Ideas \& Applications, World Scientific.

Skyttner, L., (2006), General Systems Theory: Problems- Perspectives- Practice, World Scientific.

Sondoss, Elsawah Joseph H.A. Guillaume, Tatiana Filatova Josefine Rook, Anthony J. Jakeman (2015) "A methodology for eliciting, representing, and analysing stakeholder knowledge for decision making on complex socio-ecological systems: From cognitive maps to agent-based models", Journal of Environmental Management 151, 500-516.

Snyder, S. (2013), The Simple, the Complicated, and the Complex: Educational Reform Through the Lens of Complexity Theory, OECD Education Working Papers, No. 96, OECD Publishing.p.11.

Swami, S. (2013) "Executive functions and decision making: A managerial review", IIMB Management Review, 25, $203-212$.

Taylor, T. R. B., David N. Ford, Shari A. Yvon-Lewisc and Eric Lindqui, (2011), "Science, engineering, and technology in the 
policy process for mitigating natural-societal risk", System Dynamics Review. 27, 173-194.

Taylor III, B.W. (2013) Introduction to Management Science, Pearson.

Yurtseven, M.K., and W. W. Buchanan [2012] "Dynamical System Theory and System Dynamics: Educational Issues", Technology Interface International Journal, Spring- Summer, pp. 96-103.

Wiek, A. and Walter, A.I. (2009)"A transdisciplinary approach for formalized integrated planning and decision-making in complex systems", European Journal of Operational Research, 197, 360-370. 